\title{
BMJ Open How good is online information on fibromyalgia? An analysis of quality and readability of websites on fibromyalgia in Spanish
}

\author{
Arturo Alioshkin Cheneguin, ${ }^{1}$ Isabel Salvat Salvat, ${ }^{2}$ Helena Romay Barrero (D) , ${ }^{3}$ \\ María Torres Lacomba (i) ${ }^{1}$
}

To cite: Alioshkin Cheneguin A, Salvat Salvat I, Romay Barrero $\mathrm{H}$, et al. How good is online information on fibromyalgia? An analysis of quality and readability of websites on fibromyalgia in Spanish. BMJ Open 2020;10:e037065. doi:10.1136/ bmjopen-2020-037065

- Prepublication history and additional material for this paper are available online. To view these files, please visit the journal online (http://dx.doi. org/10.1136/bmjopen-2020037065).

Received 16 January 2020 Revised 04 June 2020 Accepted 05 June 2020

\section{Check for updates}

(c) Author(s) (or their employer(s)) 2020. Re-use permitted under CC BY-NC. No commercial re-use. See rights and permissions. Published by BMJ.

${ }^{1}$ FPSM Research GroupPhysical Therapy Department, University of Alcalá de Henares, Madrid, Spain

${ }^{2}$ Department of Medicine and Surgery and Institute for Health Research Pere Virgili, Rovira i Virgili University, Tarragona, Catalunya, Spain

${ }^{3}$ Faculty of Physical Therapy and Nursing, University of Castilla-La Mancha, Toledo, Spain

Correspondence to Professor Helena Romay Barrero;

Helena.Romay@uclm.es

\section{ABSTRACT}

Objective To assess the content, quality and readability of websites with information on fibromyalgia in Spanish. Methods Websites were retrieved entering the keyword 'fibromyalgia' in Google, Yahoo! and Bing, and by searching records of patients associations in Spain and Latin America. The Bermúdez-Tamayo and DISCERN questionnaires were employed for evaluating quality and content, and INFLESZ for readability. Statistical analysis was conducted using IBM SPSSV.24 (Chicago, USA). Results Three hundred and five websites were found. After applying the exclusion criteria, 73 websites were analysed. Websites retrieved by search engines obtained median scores of 27.0 (interquartile interval (IQI): 24.532.0) with DISCERN, 35.0 (IQI: 31.0-40.5) with BermúdezTamayo and 53.7 (IQI: 47.4-56.2) with INFLESZ, whereas those from patients associations scored 21.0 (IQI: 19.223.8), 26.0 (IQI: 25.0-31.0) and 51.7 (IQI: 47.9-55.1), respectively. In general, content was not up-to-date. Conclusions Overall quality was medium-low, content quality was very low and readability was poor. Further effort is needed to guarantee meeting quality criteria and accessing updated, relevant, and legible information. This study exposes the quality and readability of websites on fibromyalgia in Spanish, which can help healthcare workers to better appraise this resource and its potential influence on the development of the pathology.

\section{INTRODUCTION}

Fibromyalgia $(\mathrm{FM})$ is a 'syndrome of widespread pain, decreased pain threshold and characteristics symptoms, including nonrestorative sleep, fatigue, stiffness, mood disturbance, irritable bowel syndrome, headache, paraesthesias and other less common features' (sic). ${ }^{1}$

A systematic review in 2017 estimated that FM affects $2.10 \%$ of the population worldwide and $2.3 \%$ in Europe. In Spain, it has a prevalence of $2.4 \%$, with an estimated yearly cost of $€ 12993$ million. $^{2}$ FM prevalence in Latin America is $1.12 \%$, ranging from $0.7 \%$ in Mexico to $0.2 \%$ in Cuba or Venezuela, a
Strengths and limitations of this study

This study is the first to examine the quality of online Spanish fibromyalgia resources.

- The online resources analysed also included all fibromyalgia patients associations registered in Spain and Latin America.

- Standardised quality and readability tools were used to assess quality and readability.

- There is no gold standard to evaluate the quality of websites.

- The outcome validity of this study is temporary, and its quality analysis can vary in the future.

variability that can result from diverse diagnosis criteria. ${ }^{23}$

Since one of the main symptoms is generalised chronic pain, ${ }^{4}$ education plays an important role in the therapeutic approach to FM. ${ }^{5}$ Research on the effect of diverse educational methods, such as cognitive behavioural therapy ${ }^{67}$ and neuroscience education, ${ }^{78}$ has increased in the last years. Strong evidence exists about the effectiveness of combining education, exercising and active coping strategies on pain, quality of life and functionality. ${ }^{9}$ Guides like the European League Against Rheumatism recommend including education among non-pharmacological treatments for $\mathrm{FM}^{10}$

The evolution of the internet and its interactive features has favoured the emergence of virtual health communities, such as patients associations, where users can share experiences and opinions and receive social support. Also, they provide a wide variety of information that affects and empowers users in their health-related decision-making. ${ }^{11}$

In addition, the internet has largely grown in the last decades. According to the National Observatory of Telecommunications and the Information Society (ONTSI), 
$60.5 \%$ of the Spanish population searches the web for health information. ${ }^{12}$ With 572 million speakers worldwide, 477 million of which are native speakers, Spanish is the third most used language in the web, and $8.1 \%$ of the almost 3885 million internet users in December 2017 employed it. ${ }^{13}$

Daraz et al exposed the preferences and needs of patients with FM when seeking information: $91 \%$ searched the web for it, specifically for treatments $(87 \%)$, resources (85\%), symptoms $(81 \%)$, implications $(79 \%)$ and coping $(79 \%)$. Of them, $93 \%$ expressed concern about information reliability and highlighted the need for reputable or medical-staff sources. ${ }^{14}$

The studies found assessing the quality of online FM information in English concluded that sites of greater quality are generally less readable and that FM information is incomplete and of low quality. ${ }^{15} 16$ The authors have not found any study on the quality and contents of websites on FM in Spanish.

The aim of this study was to identify information resources for patients with FM, available online and in Spanish, and to evaluate their quality, content and readability.

\section{METHODS}

\section{Design and search strategy}

A descriptive study was conducted where websites providing information on FM were analysed for quality, content and readability using standardised, validated tools. ${ }^{17-20}$ Figure 1 shows a flow chart describing the stages of the search process.

'Fibromyalgia' was chosen as keyword for the web search given its popularity in 'Google Trends' ${ }^{21}$ (trends. google.es) and a filter was applied for 'Last 12 months' and 'Worldwide'. Google (google.es), Yahoo! (es.yahoo. com) and Bing (bing.com) were the employed search engines based on their popularity in 'Statcounter', both in Spain and Latin America. All the above-mentioned searches were carried out in April 2019.

Two researchers conducted an online search independently after emptying the cache and history and deactivating location in the computer, with no further filters being applied. GPS was deactivated to prevent the engines from displaying only websites close to the location of the researchers. Since users do not appear to seek information past the first 20 retrieved websites, each researcher selected the first 20 hits from each engine. Additionally, the researchers independently looked for websites of FM associations in Spain and Latin America among their relevant national Public Registry of Associations as of May 2019.

\section{Selection criteria}

All websites in Spanish containing FM information were included.

The following sites were excluded: broken links, duplicates, exclusively offering advertisements; mainly offering information in PDF, images or videos; news or entries from a journal requiring subscription or payment to access information, without a main page explaining FM, and whose content consisted of links to other sites or documents; not allowing a readability analysis. The included webpages were classified according to the typology of the website. The following typologies were established: nonprofit; commercial (websites selling products or services); institutional (government and professional (organisations with professional medical qualification)); free-of-charge information and media owners.

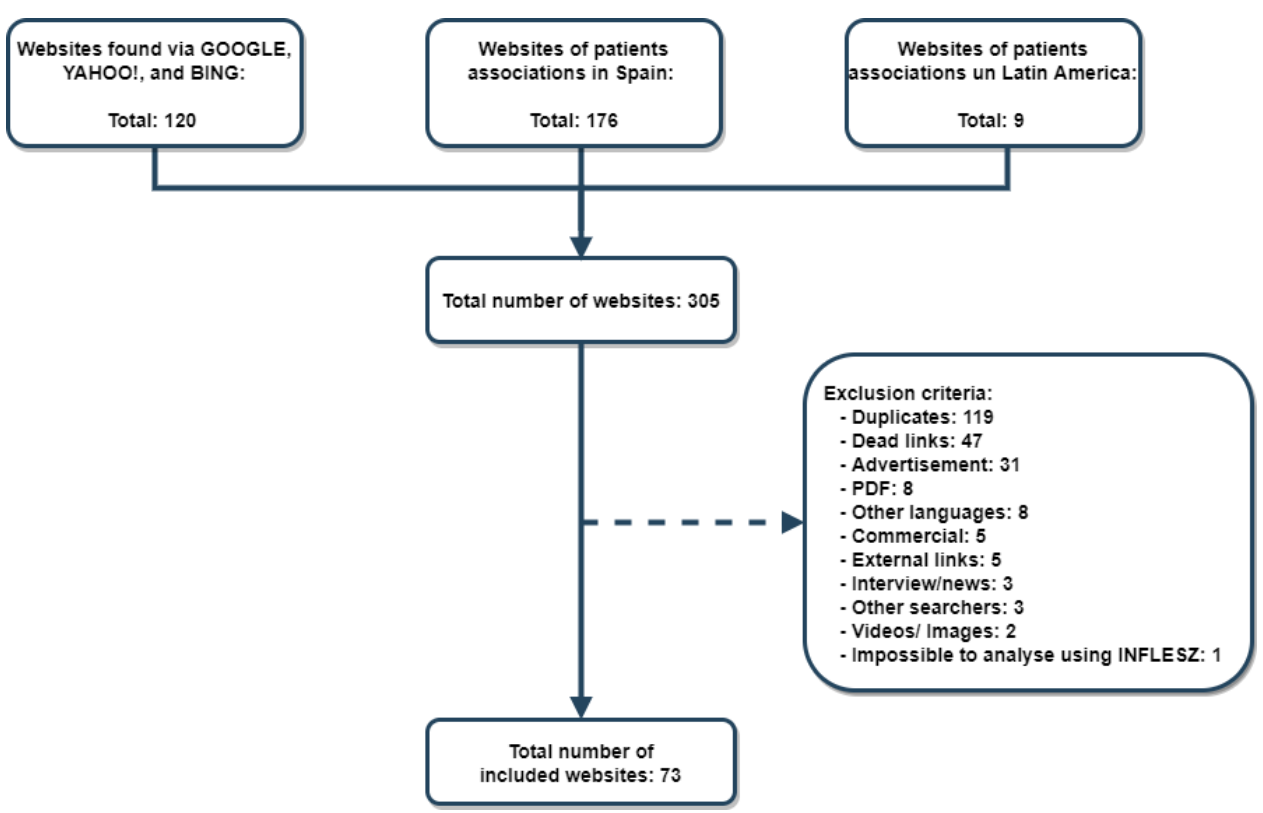

Figure 1 Flow chart showing the selection process of websites. 


\section{Tools for quality and readability analyses}

The researches independently evaluated the content of the included websites using the DISCERN and BérmudezTamayo questionnaires and the INFLESZ scale.

The DISCERN questionnaire is a valid, reliable tool initially developed for assessing the quality of written information on health-treatment options, which was subsequently applied to websites. ${ }^{19}{ }^{20}$ It comprises three sections with 16 items: the first 8 assess general reliability of the content, the following 7 evaluate quality of treatment options, and the third section assigns an overall score to the publication. Each question receives a score ranging from $1=$ no to $5=y e s$, allowing intermediate scores (2, 3 and 4). Since the questionnaire poses no interpretation about its score, the researchers agreed on these values for items concerning: content relevance, information sources, date of content, additional support resources, description of how the treatment works and its relevant risks and benefits, treatment options and shared decision-making. The overall score range is $16-80$, with higher scores having better content quality, defined as follows: $16-29=$ very low; $30-42=$ low; $43-55=$ =moderate; 56-68=good and 69-80=excellent.

The Bermúdez-Tamayo questionnaire ${ }^{18}$ evaluates the quality of health websites in Spanish following the recommendations by the main ethical codes and law in Spain and Europe. ${ }^{22} 23$ This validated tool shows adequate reliability (kappa $\geq 0.60$ ) for 12 of its 18 items and comprises 6 sections: transparency and absence of conflicts (5 items), authorship (2 items), personal data protection (ie, the website must describe how the information on an identified or identifiable individual is protected and how data are processed) (1 item), updating of information $(1$ item), responsibility (meaning the possibility of contacting someone responsible for the website to send comments and/or suggestions, whether they offer online consultations and if the team responsible for addressing consultations can be identified) ( 4 items) and accessibility (5 items). Each item receives a score of 0-3 (0=does not apply; $1=$ no; $2=$ partially; $3=y e s$, so that the overall score ranges from 17 to 54 , with higher scores reflecting better quality, defined as follows: 17-25=very low, 26-33=low, 34-40=moderate, $41-47=$ good and 48-54=excellent. The researchers agreed on items concerning: purpose and objective of the website; information sources; publication date; and ease of content searching.

INFLESZ is a readability scale, available online and validated in Spanish. Readability is 'the ensemble of typographic and linguistic features of written texts that allow for their easy reading and understanding' (sic). ${ }^{24}$ INFLESZ is considered to be more the most suitable scale for the Spanish-speaking population. This tool allows entering the text or its URL online and provides a score ranging from 0 to 100 , with ease of text readability defined as: very difficult $<40$, slightly difficult $=40-55$, normal $=55-$ 65 , fairly easy $=65-80$ and very easy $>80$. According to this scale, health texts are more likely to be understood if they score $>55 .^{17}$
Since none of the above-mentioned tools takes into consideration certain issues that are considered important by subjects with $\mathrm{FM}^{14}$ or that have been reported to be of relevance in prior studies, ${ }^{510}$ the following data were also recorded: terminology (FM conceptualisation, meaning whether FM is designated as a disease or not, and the terms used to define FM, such as generalised pain syndrome, chronic pain or central sensitivisation syndrome); relevance of information on diagnosis (type of diagnosis, whether based on tender points as per the criteria by Wolfe in $1990^{25}$ or in $2010,{ }^{26}$ or based on symptomatology) and treatment (ie, if they mention the treatments that are most supported by scientific evidence, such as therapeutic education of the patient and therapeutic exercising); support (social, family, etc); symptoms (FM-related symptoms) $^{26}$ and both pharmacological and non-pharmacological treatments (type of treatment).

\section{Data collection and analysis}

Data were collected independently by two researchers who discussed and agreed on each item or website when there was no consensus.

IBM SPSS V.24 (Chicago, USA) software was used for the statistical analysis. Quantitative variables were described by their median and interquartile interval (IQI) assuming the data did not fit a normal distribution, which was verified using the Shaphiro-Wilk test. Categorical variables were described by their absolute frequencies and percentages. Quantitative variables from both categories of websites (retrieved by search engines or from patients associations) were compared using the non-parametric Mann-Whitney U test. Additionally, Fisher's exact test was used to compared the typology of the 10 first hits by search engines. All comparisons were two-tailed and statistical significance was set at $\mathrm{p}<0.05$.

\section{Patient and public involvement}

This research was done without patient involvement. Patients were not invited to comment on the study design and were not consulted to develop patient relevant outcomes or interpret the results. Patients were not invited to contribute to the writing or editing of this document for readability or accuracy.

\section{RESULTS}

\section{Characteristics of analysed websites}

A total of 305 websites were found using search engines and from patient associations in Spain and Latin America. After applying the exclusion criteria, 73 sites were included (figure 1, see online supplementary appendix 1) and classified as follows: $53(72.6 \%)$ non-profit (eg, fundacion-canna.es), 7 (9.5\%) commercial (eg, hhp. es, kernpharma.com, sanitas.es), 6 (8.2\%) institutional ( government (eg, niams.nih.gov/es) and professional (eg, portal.hospitalclinic.org)), 4 (5.4\%) providing free-of-charge information (eg, www.fisterra.com) and 3 $(4.1 \%)$ from media owners (eg, www.infosalus.com). Of 
Table 1 Typology of the top 10 websites retrieved by search engines

\begin{tabular}{|c|c|c|c|c|c|c|c|c|}
\hline \multirow[b]{3}{*}{ Typology of website } & Google & Yahoo! & Bing & \multirow[b]{3}{*}{ P value* } & \multirow{2}{*}{$\begin{array}{l}\text { Google } \\
\mathrm{N} \text { in top } 10 \\
(\%)\end{array}$} & \multirow{2}{*}{$\begin{array}{l}\text { Yahoo! } \\
\mathrm{N} \text { in top } 10 \\
(\%)\end{array}$} & \multirow{2}{*}{$\begin{array}{l}\text { Bing } \\
\mathrm{N} \text { in top } 10 \\
(\%)\end{array}$} & \multirow[b]{3}{*}{ P value } \\
\hline & $\begin{array}{l}\mathrm{N} \text { in overall } \\
\text { search }(\%)\end{array}$ & $\begin{array}{l}\mathrm{N} \text { in overall } \\
\text { search (\%) }\end{array}$ & $\begin{array}{l}\mathrm{N} \text { in overall } \\
\text { search }(\%)\end{array}$ & & & & & \\
\hline & $\mathrm{n}=25$ & $\mathrm{n}=25$ & $\mathrm{n}=\mathbf{2 5}$ & & $n=10$ & $n=10$ & $n=10$ & \\
\hline Commercial & $8(32 \%)$ & $3(12 \%)$ & $5(20 \%)$ & 0.261 & $3(30 \%)$ & $1(10 \%)$ & $2(20 \%)$ & 0.847 \\
\hline Non-profit & $5(20 \%)$ & $2(8 \%)$ & $5(20 \%)$ & 0.46 & $2(20 \%)$ & $0(0 \%)$ & $2(20 \%)$ & 0.507 \\
\hline Free of charge information & $5(20 \%)$ & $5(20 \%)$ & $5(20 \%)$ & 1 & $1(10 \%)$ & $3(30 \%)$ & $3(30 \%)$ & 0.642 \\
\hline
\end{tabular}

Among websites from patient associations, 44 were from Spain and 3 from Latin America (Argentina, Chile and Venezuela) (online supplementary appendix 1).

${ }^{*}$ Fisher's exact test.

them, seven $(9.5 \%)$ and four $(5.4 \%)$ were websites translated from English and Catalan, respectively. In terms of typology of websites found by search engines, no statistically significant differences in frequency were found between the top 10 and the totality of the included ones (table 1).

\section{Type of information}

Websites retrieved by search engines

Figure 2 shows the type of information in the websites retrieved by search engines.

In terms of illness conceptualisation, six websites (24\%) mentioned that FM is acknowledged as an illness by WHO. Barely any mentioned central sensitisation or central sensitisation syndrome, and none named other terms like dysfunctional pain.

The least cited symptoms were paraesthesia ( 11 websites; $44 \%)$ together with morning stiffness and anxiety (15 websites; $60 \%$ ). The most cited symptoms were pain (25 websites; $100 \%$ ) followed by sleep disorders (23 websites; $92 \%$ ) and fatigue (21 websites, $84 \%$ ).

The most cited pharmacological treatments were antidepressants (22 websites; $88 \%$ ), followed by painkillers (17 websites; 68\%) and antiepileptic drugs (15 websites; 64\%). Muscle relaxants and non-steroid antiinflammatory drugs were named in eight websites (32\%). In terms of non-pharmacological treatments, the most highlighted physiotherapy techniques were massage (10 websites; 40\%), stretching (4 websites; 16\%) and locally applied heat (3 websites; 12\%). The most frequently mentioned alternative therapies were yoga (10 websites; $40 \%$ ), acupuncture (9 websites; $36 \%$ ) and Tai Chi (5 websites; $20 \%$ ).

In terms of advice, sleep strategies were the most recommended, specifically implementing sleep habits (seven websites; 28\%), and moderating activity and daily life pace, as well as mentality changes. Stress (seven websites; $28 \%$ ), weather changes (cold, humidity) with anxiety/ stress (six websites; 24\%) and excessive physical activity (three websites; 12\%) were highlighted as aggravating factors.
Websites from patients associations

Figure 3 shows the type of information in the websites retrieved from patients associations websites.

Among websites mentioning that FM is a disease, 10 (20.8\%) included acknowledgement by WHO, 1 (2.1\%) specifically cited that FM is in the International Classification of Illnesses and $10(20.8 \%)$ mentioned both facts. In terms of symptoms, the least mentioned were hypersensitivity (15 websites; $31.2 \%$ ) paraesthesia (28 websites; $58.3 \%$ ) and depression (29 websites; $60.4 \%$ ). The most cited symptoms were pain (44 websites; $91.7 \%$ ), followed by sleep disorders (40 websites; $83.3 \%$ ) and fatigue (37 websites ; 77.1\%). In terms of pharmacological treatment, antidepressants (19 websites; 39.6\%), painkillers (15 websites; $31.2 \%$ ) and muscle relaxants (9 websites; $18.7 \%)$ were the most mentioned, and $9(18.7 \%)$ of the websites including pharmacological treatment did not mention any in particular. The most frequently cited physiotherapy techniques were massage (eight websites; $16.7 \%$ ), stretching (five websites; $10.4 \%$ ) and locally applied heat (four websites; $8.3 \%$ ). Finally, the most cited alternative therapies were yoga and acupuncture (eight websites; $16.7 \%$ ) and Tai Chi (seven websites; $14.6 \%$ ).

In terms of recommendations, the most common advice was avoiding aggravating factors, like stress (nine websites; $18.7 \%$ ), and improving sleep habits (six websites; $12.5 \%$ ). The most commonly mentioned aggravating factors were weather changes (cold, humidity) (nine websites; $18.7 \%$ ), stress/anxiety (seven websites; $14.6 \%$ ) and excessive physical activity (five websites; $10.4 \%$ ).

\section{Quality of health information}

Websites retrieved by search engines

The overall quality as measured by the DISCERN ${ }^{20}$ obtained a median score of 27.0 (IQI: 24.5-32.0): 18 $(72.0 \%)$ scored 16-29 points (very low), 6 (24.0\%) obtained 30-42 points (low) and only $1(4.0 \%)$ website reached 43-55 points (moderate). All categories scored $<2$ (table 2). Regarding the quality of information on treatment choices, only 1 website was retrieved by search engines $(4.0 \%)$ and 10 websites from patient associations 


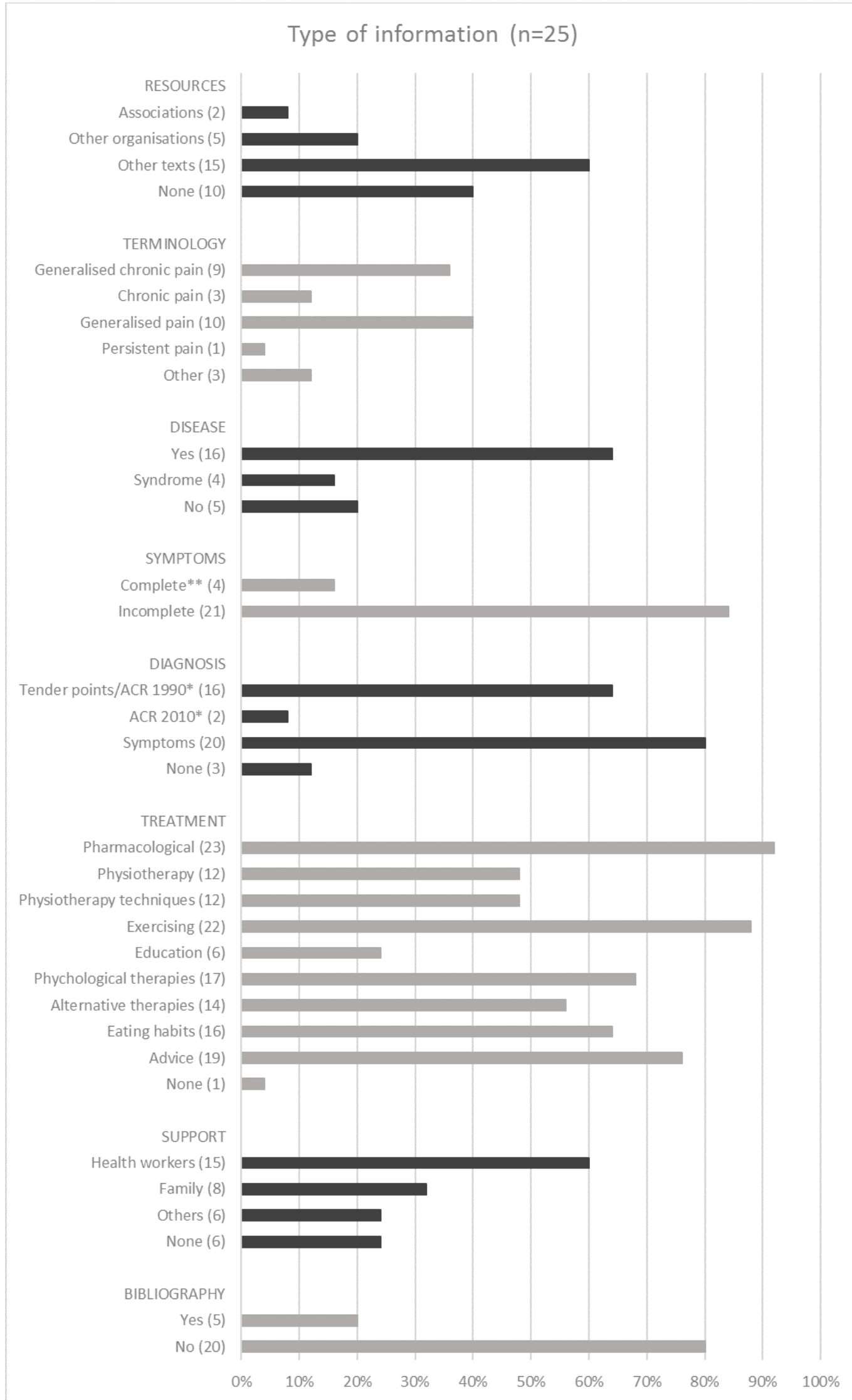

Figure 2 Type of information in websites retrieved by search engines. ${ }^{*}$ Diagnostic criteria for fibromyalgia by the American College of Rheumatology (ACR). ${ }^{*}$ Complete symptoms when including generalised pain, hypersensitivity (allodynia, hyperalgesia and/or exacerbated sensitivity to stimuli in addition to pain), fatigue, sleep disorders, cognitive disorders, anxiety, paraesthesia, morning stiffness and depression). 


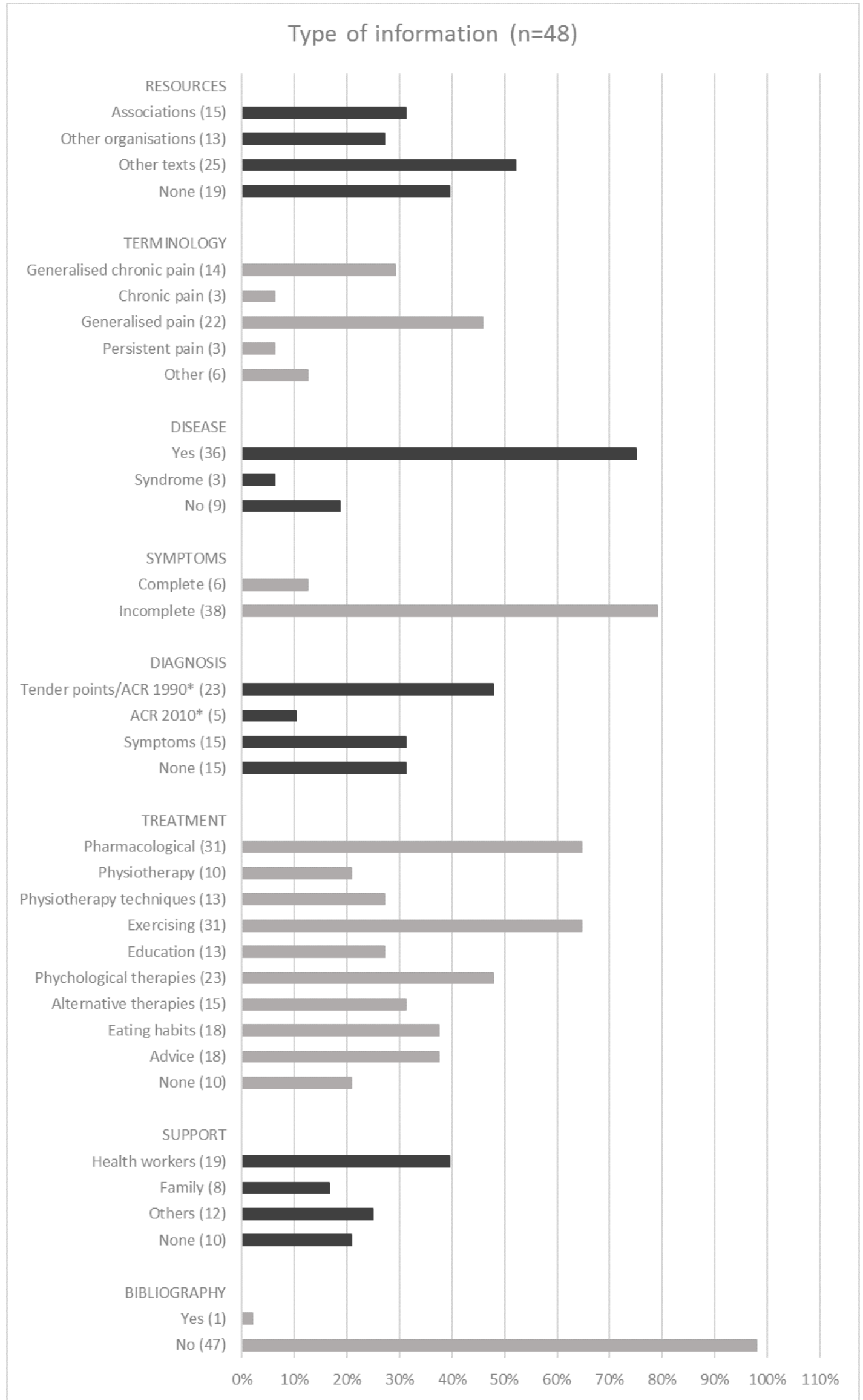

Figure 3 Type of information in websites from patients associations. ${ }^{*}$ Diagnostic criteria for fibromyalgia by the American College of Rheumatology (ACR). 
Table 2 Score for the quality of health information by category according to the DISCERN questionnaire

\begin{tabular}{|c|c|c|c|c|c|}
\hline \multirow[b]{2}{*}{ Category } & \multicolumn{2}{|c|}{$\begin{array}{l}\text { Websites } \\
\text { retrieved by } \\
\text { search engines }\end{array}$} & \multicolumn{2}{|c|}{$\begin{array}{l}\text { Websites } \\
\text { of patients } \\
\text { associations }\end{array}$} & \multirow[b]{2}{*}{ P value } \\
\hline & Median & IQI & Median & IQI & \\
\hline $\begin{array}{l}\text { Reliability of } \\
\text { the publication }\end{array}$ & 1.6 & $1.5-1.8$ & 1.3 & $1.2-1.5$ & $<0.001$ \\
\hline $\begin{array}{l}\text { Quality of } \\
\text { information } \\
\text { on treatment } \\
\text { options }\end{array}$ & 1.7 & $1.4-2.0$ & 1.3 & $1.0-1.4$ & $<0.001$ \\
\hline Overall score & 2 & $2.0-3.0$ & 2 & $1.0-2.0$ & $<0.001$ \\
\hline
\end{tabular}

*Mann-Whitney U test.

IQI, interquartile interval.

(20.8\%) did not offer any information on treatment choices.

Websites from patients associations

According to the DISCERN, ${ }^{20}$ the overall quality was very low, with a median score of 21.0 (IQI: 19.2-23.8): 44 websites $(91.7 \%$ ) scored 16-29 (very low) and other 4 websites $(8.3 \%)$ scored $30-42$ (low). All the categories scored $<2$ (table 2). Statistically significant differences were found in all categories between websites found by search engines and from patients associations (table 2). The overall DISCERN score was lower for those from patients associations websites, $\mathrm{p}<0.001$ (figure 4).

\section{Quality of websites}

Websites retrieved by search engines

Using the Bermúdez-Tamayo questionnaire,${ }^{18}$ the overall quality was moderate, with a median score of 35.0 (IQI: 31.0-40.5): 9 websites (36\%) obtained a score of 26-33 (low), 10 (40\%) scored 34-40 (moderate), 5 (20\%) obtained 41-47 points (good) and only 1 achieved a score of 48-54 (excellent). The category achieving the lowest
Table 3 Score for the quality of websites by category according to the Bermúdez-Tamayo questionnaire

\begin{tabular}{|c|c|c|c|c|c|}
\hline \multirow[b]{2}{*}{ Category } & \multicolumn{2}{|c|}{$\begin{array}{l}\text { Websites } \\
\text { retrieved by } \\
\text { search engines }\end{array}$} & \multicolumn{2}{|c|}{$\begin{array}{l}\text { Websites } \\
\text { of patients } \\
\text { associations }\end{array}$} & \multirow[b]{2}{*}{$P$ value* } \\
\hline & Median & IQI & Median & IQI & \\
\hline $\begin{array}{l}\text { Transparence } \\
\text { and absence } \\
\text { of conflict of } \\
\text { interests }\end{array}$ & 2.6 & $1.8-2.6$ & 1 & $1.0-1.8$ & $<0.001$ \\
\hline Authorship & 1 & $1.0-2.0$ & 1 & $1.0-1.0$ & 0.002 \\
\hline $\begin{array}{l}\text { Protection of } \\
\text { personal data }\end{array}$ & 3 & $3.0-3.0$ & 1 & $1.0-3.0$ & 0.001 \\
\hline $\begin{array}{l}\text { Information } \\
\text { updating }\end{array}$ & 1 & $1.0-1.0$ & 1 & $1.0-1.0$ & $<0.001$ \\
\hline Responsibility & 1.3 & $1.3-2.0$ & 1.3 & $1.3-1.3$ & $<0.001$ \\
\hline Accessibility & 2 & $1.8-2.3$ & 2 & $1.8-2.0$ & 0.342 \\
\hline
\end{tabular}

*Mann-Whitney U test.

IQI, interquartile interval.

score was updating of information (table 3 ). Statistically significant differences were observed in all the categories between the websites retrieved by search engines and those from patients associations, with the exception of accessibility (table $3, \mathrm{p}=0.342$ ).

Websites from patients associations

According to the Bermúdez-Tamayo questionnaire, ${ }^{18}$ the general quality was also low, with a median score of 26.0 (IQI: 25.0-31.0): 24 sites $(50.0 \%)$ obtained a score of 17-25 (very low), 20 (41.7\%) scored 26-33 (low), 3 (6.2\%) obtained 34-40 points (moderate) and only 1 (2.1\%) achieved 41-47 points (good). Scores were low for all the categories, among which updating of information scored the lowest (table 3).

Statistically significant differences were noted in the total score of the Bermúdez-Tamayo questionnaire

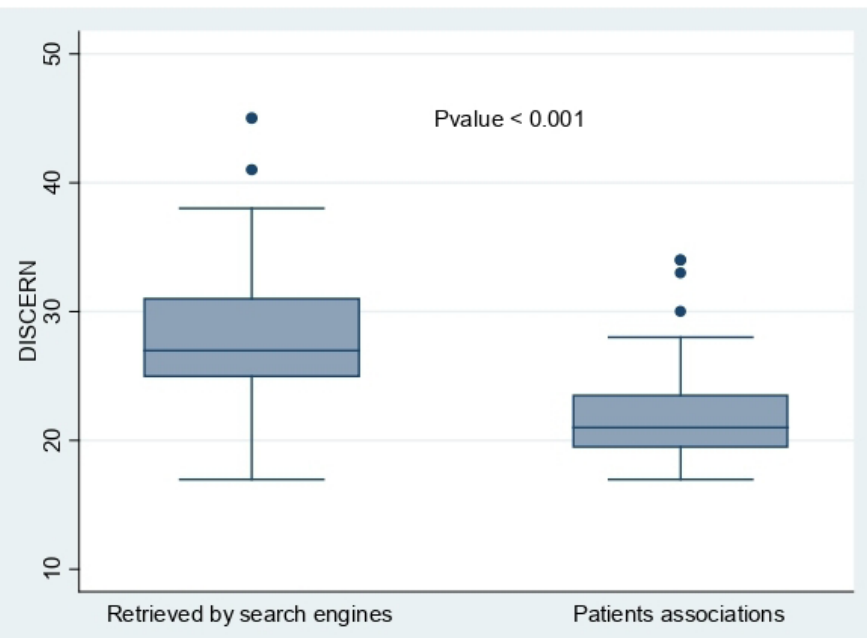

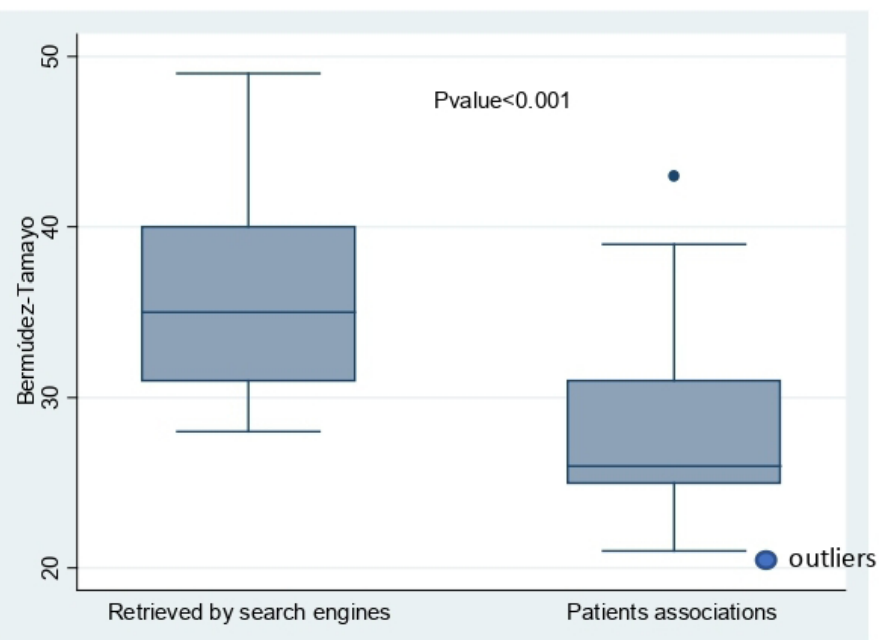

Figure 4 Comparison of the quality of websites according to the DISCERN and Bermúdez-Tamayo questionnaires between websites retrieved by engines and from patients associations. 


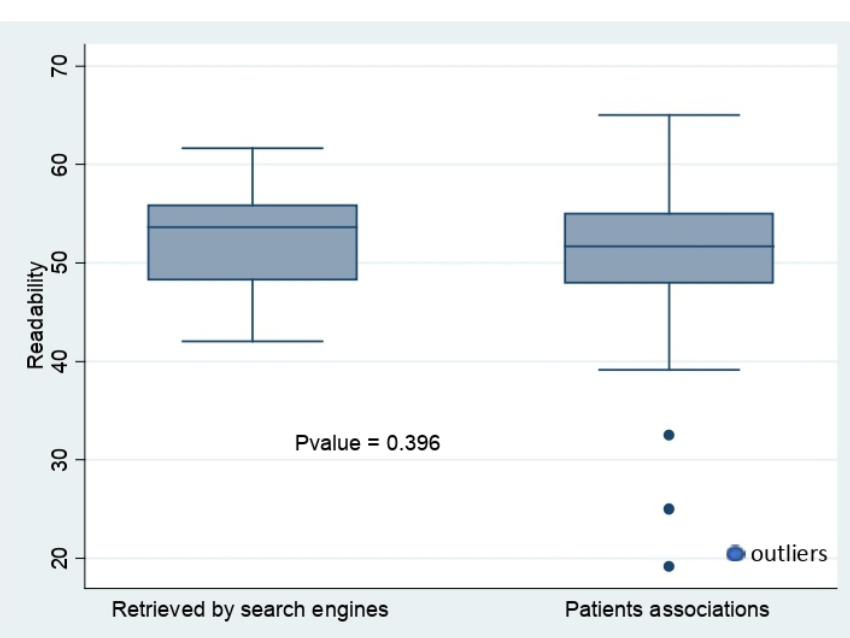

Figure 5 Comparison of readability between websites retrieved by engines and from patients associations.

between the websites found by search engines and those from patients associations $(\mathrm{p}<0.001$, figure 4$)$.

\section{Readability}

Websites retrieved by search engines

With a median score of 53.7 (IQI: 47.4-56.2), readability was found to be 'slightly difficult': 15 websites $(60.0 \%)$ were categorised as 'slightly difficult' (40-55 points) and $10(40.0 \%)$ as 'normal' in terms of readability (55-65 points).

\section{Websites from patients associations}

Overall readability was also 'slightly difficult' with a median score of 51.7 (IQI: 47.9-55.1): 4 websites (8.3) were considered 'very difficult' $(<40), 32(66.7 \%)$ 'slightly difficult' (40-55), 11 (22.9\%) were 'normal' (55-65) and $1(2.1 \%)$ was 'fairly easy' (65-80) to read.

No statistically significant differences in readability were observed between websites found by search engines and from patients associations $(\mathrm{p}<0.396)$ (figure 5$)$.

\section{DISCUSSION}

The outcomes obtained with the tools this study employed suggest that quality of FM websites in Spanish, as retrieved by the main search engines, tend to be of medium-low quality, whereas those from both Spanish and international patients associations tend to be of very low quality. Overall, content quality was very low, and readability was 'slightly difficult'.

Website quality, readability and content varied among websites, similarly to previous research on $\mathrm{FM}^{1516}$ and other chronic conditions. ${ }^{27}{ }^{28}$ As far as the authors know, this study is the first to assess quality of websites on FM in Spanish and the only one including an analysis of websites from FM patients associations. The remainder of the articles that were found while analysing websites quality ${ }^{29} 30$ do not specifically mention FM.

\section{Methodology}

This study employed validated, widely used questionnaires for analysing website quality. LIDA and DISCERN are the tools most frequently used for this purpose, ${ }^{20} 31$ which is the Bermúdez-Tamayo questionnaire for websites in Spanish. ${ }^{18}$

LIDA is a tool that assesses healthcare websites for content and information design, ${ }^{31}$ with accessibility, usability and reliability of information being the three main categories. The Bermúdez-Tamayo questionnaire was originally validated in Spanish ${ }^{18}$ and also includes these categories but, as it mainly contemplates aspects of the website as such and not its contents, the DISCERN questionnaire was employed, a tool that has been broadly used in research, both in English and Spanish. ${ }^{16}$ 27-29 32 None of the employed questionnaires interprets the results or qualifies the score into quality levels. This leads researchers to propose their own levels and, although these tend to be very similar, they can be interpreted in different ways hindering comparison between outcomes. This trial created five quality levels for all the items.

Another important aspect of websites is readability. Studies assessing English websites tend to use Flesch Reading Ease score maps ${ }^{1628}$ and Flesch-Kincaid. ${ }^{283233}$ Both $^{3435}$ provide a score from 0 to 100 , where higher scores indicate texts that are easier to read. For the general public, 60 is considered an acceptable value. Flesch-Kincaid ${ }^{34}$ also indicates the necessary education level to understand a text. Studies evaluating Spanish websites use the INFLESZ scale, ${ }^{172730}$ which was created after the Flesch scale was reviewed $^{35}$ and is considered one of the Spanish-adapted versions of the former and Flesch-Szigrist ${ }^{36}$ scales. Comparisons between INFELSZ and FLESH scores can be found in online supplementary appendix 2.

\section{Websites characteristics and type of information}

There were differences in the outcomes between websites found by search engines and those from patients associations. The greatest differences were observed using the Bermúdez-Tamayo questionnaire, ${ }^{18}$ where websites retrieved by search engines obtained higher scores. This could be due to the non-profit character of websites of patients associations and because most seem to have been created by patients with FM with no mention about whether the contents have been selected by a professional expert in FM or a scientific board, and also the websites do not seem to be created by webpage developers but more likely using a non-paid website development tool, such as webnode. ${ }^{37}$ In contrast, websites found by search engines belong to different categories, like commercial or institutional, which can involve some sort of funding for their development and management. However, this is a hypothesis, since most websites do not state their funding body. This outcome differs from that by Basavakumar et $a l^{15}$ that found websites from not-for-profit organisations to be the most complete ones. This could be due to the different tools and methods employed in the different 
studies to analyse the quality and type of included websites. Additionally, the non-for-profit websites in the above-mentioned study only accounted for $9 \%$ of the total, and it does not specify if it included websites from patients associations. The websites from patients associations included in this study (64\% of assessed websites) are all non-for-profit and show the worst quality.

\section{Type of information}

Symptoms, treatment and diagnosis were the most commonly tackled information in the assessed sites. Other issues of importance for patients with FM, such as support, ${ }^{1438}$ are dealt with superficially and briefly, chiefly naming the importance of the doctor for determining pharmacological treatment.

A very mechanistic, vague vision of FM, with little scientific evidence, was generally observed. In terms of conceptualisation of FM, no website was found that mentioned dysfunctional pain, no difference was made between clinical diagnosis or diagnosis criteria for research, and diagnostic points were those of 1990 even if Wolfe warned about the risk this implied when used for clinical practice already in $2003 .^{39}$ Provided treatment alternatives can cause nothing but confusion due to the high variability found, little correlation with scientific literature (neither massage nor stretching are backed by scientific evidence $^{4041}$ and, in certain cases, they can be counterproductive), and the superficial manner in which they are covered. For instance, education is one of the least mentioned treatments despite being one of the most recommended ones, ${ }^{510}$ and neuroscience education is not found in any of the websites citing it even if its effectiveness for treating pain has been proven. ${ }^{79}$ The type or frequency of recommended physical exercise was not specified in any case despite being one of the most mentioned treatments in the internet. ${ }^{104142}$ In terms of psychological therapies, cognitive behavioural therapy was mentioned in some websites but in a very vague way and without mentioning exiting evidence for it. ${ }^{6}$

\section{Quality of health information}

Information quality and reliability were assessed via the DISCERN questionnaire. ${ }^{20}$ The outcome showed that FM contents in websites in Spanish were of very low quality. In the study by Daraz et al, ${ }^{16}$ which also employed this tool, $36 \%$ of the 25 included websites were qualified as 'marginal', $32 \%$ as 'good' and $32 \%$ as 'very good'. Of the websites found by search engines in this study, $72 \%$ were classified as 'very low quality', $24 \%$ as 'low quality' and $4 \%$ as 'moderate quality'. Similarly, $91.6 \%$ of the websites from patients associations obtained scores classified as 'very low quality' and $8.3 \%$ as 'low quality'. In this regard, the quality of websites analysed in this study seemed to be lower than that in the work by Daraz et al. ${ }^{16}$ It is necessary to acknowledge that the maximum score in the study by Daraz et $\mathrm{al}^{16}$ was 75 points, since the last item was excluded; had this study proceeded similarly and followed the categories as Daraz et al, ${ }^{16} 84.0 \%$ of websites found by search engines would be categorised as 'marginal' and $16.0 \%$ as 'good', while there would not be changes in quality for patients associations websites. The mean score obtained by Daraz et $a l^{16}$ using the DISCERN questionnaire ${ }^{20}$ was considerably higher than that obtained in this study for websites found by search engines (26.4) and from patients associations (20.9). Daraz et $a l^{16}$ also reported a mean score of 2.5 for the 15 items, whereas none of the three categories in the DISCERN questionnaire ${ }^{20}$ scored $>2$ in this trial. This could be due to the fact that our two independent researchers agreed on the score of some items and the necessary minimums for intermediate scores $(2$, 3 and 4), thus minimising potential variability, an aspect not mentioned by Daraz et al. ${ }^{16}$

On the other hand, the study by Kaicker et $a l^{32}$ employed the DISCERN questionnaire ${ }^{20}$ for assessing the quality of contents of 161 websites in English found using Google, Yahoo! and MSN, by entering 'pain', 'chronic pain', 'back pain', 'arthritis' and 'fibromyalgia' as search keywords. The mean score was 55.9 (moderate quality). The higher score they obtained compared with this study could result from the fact that Kaicker et al did not analyse specific websites for FM.

Washington $e t a l^{33}$ designed their own questionnaire to assess the content of 240 websites in English found using Google, Yahoo! and MSN and entering 'pain', 'chronic pain', 'back pain', 'arthritis' and 'fibromyalgia' as keywords. They concluded that the overall quality was quite low, which is in agreement with the outcome of this study despite using a different methodology.

\section{Quality of websites}

Website quality and how to assess it is a controversial issue, partly because there is a subjective component to quality that is difficult to quantify. ${ }^{18}$ This study employed the Bermúdez-Tamayo questionnaire, ${ }^{18}$ the most used tool in Spanish to evaluate quality-related criteria for websites. Using this questionnaire, updating of information was the category that obtained the lowest score, both for websites found by search engines and those from patients associations. This is in agreement with other trials using this tool ${ }^{30434}$ and results from the fact that only three of the included websites found by search engines specified the last date of information update and only two made a partial statement in this regard, whereas none of the sites of patients associations complied with this item. Several ethical codes request that the latest update is clearly stated for each website and each of its components. Additionally, e-Europe and the American Medical Association require that a revision be conducted on the pertinence of the provided information based on the latest evidence. ${ }^{18}$ Basavakumar et $a l^{15}$ analysed 148 webpages, using the $J A M A$ score (ranged between 0 and 4) and found that only 63 webpages $(43 \%)$ met the quality threshold of $\geq 3$.

\section{Readability}

Reducing text comprehensibility to a mathematical equation is difficult. ${ }^{45}$ However, readability indexes are 
a well-accepted approach for improving text readability and comprehension. ${ }^{46}$ Also, the importance of this aspect must be emphasised, since requiring high reading skills can reduce information accessibility and potentially exclude users with low literacy. ${ }^{47}$

In this study, websites found both by search engines and from patients associations were categorised as 'slightly difficult to read', with scores of 52.39 and 47.70 , respectively. The recommended minimum score for health information is $55,{ }^{17}$ which is probably the reason why the general public has difficulties understanding the information provided in the included websites. Other studies using the INFLESZ scale ${ }^{17}$ to analyse readability obtained similar outcomes. ${ }^{2730}$ Readability can vary among websites due to the use of technical terms, such as FM, which appears to have low readability. ${ }^{16}$ The readability degree of most of the websites assessed by Daraz et $a l^{16}$ corresponded with a 10th-12th school grade level, whereas the recommended level is that of 6 th grade. ${ }^{48}$ Kaicker $e t a l^{22}$ obtained similar results, as is the case of our study with a score on the INFLESZ scale ${ }^{17}$ of 40-55 (slightly difficult), which corresponds with high-school reading level. ${ }^{17}$ Using a standardised online tool (https://www.webfx. com/tools/read-able/), Basavakumar et al ${ }^{15}$ found that only $92 \%$ of websites met the recommended readability.

\section{Limitations}

There are limitations to this study. Content updates in the internet must be taken into consideration. Since newly created websites can be incorporated, or the assessed sites can undergo revisions and modifications, the outcome validity of this study is temporary, and its quality analysis can vary in the future.

Additionally, using different search engines, on different dates or entering other terms can modify the results. ${ }^{48}{ }^{49}$ Since 'fibromyalgia' was the only term entered as keyword, it is possible that websites consulted by subjects with FM were omitted in this trial, such as those on chronic pain. Additionally, by including only the first 20 links displayed by three search engines, some resources of interest could have been missed. This is a usual limitation in any internet search. However, this study tried to reproduce the most common pattern a Spanish-speaker would follow: over 95\% of searches in Spain are done via Google ${ }^{5051}$ by entering the name of the disease or one of its symptoms. ${ }^{12}$ Therefore, assessing 20 websites of those retrieved by Google/Yahoo!/Bing appears to be sufficiently exhaustive, especially considering that the general population do not consult any site further than the second one. ${ }^{52}$

\section{Clinical practice implications}

Since patients with FM often consult the internet to better understand their illness and how to manage it, ${ }^{14}{ }^{21}$ which can be an aid or a barrier for treating it,$^{53}$ knowing about information available online can be useful for health workers. The paucity of information on the diagnosis, treatment options and conceptualisation of FM this work found must be compensated with correct information by health workers, especially considering that education is an essential part of its treatment. ${ }^{10}$

\section{CONCLUSIONS}

The quality of websites on FM in Spanish is moderate-low, very low in terms of content and their readability is slightly difficult. Additionally, the provided contents are very diverse, often lack scientific evidence and are not up-todate. Greater efforts are required to guarantee that FM websites comply with quality criteria and offer updated information, relevant, of quality, and readable.

Contributors AAC: conceptualisation; methodology; investigation; writing—original draft. MTL: conceptualisation; methodology; software; validation; investigation; formal analysis; resources; data curation; writing —original draft; visualisation; supervision; writing — review and editing. ISS: validation; writing—original draft. HRB: writing—original draft; visualisation; writing — review and editing.

Funding The authors have not declared a specific grant for this research from any funding agency in the public, commercial or not-for-profit sectors.

Competing interests None declared.

Patient consent for publication Not required.

Provenance and peer review Not commissioned; externally peer reviewed.

Data availability statement All data relevant to the study are included in the article or uploaded as supplementary information. Additional data are available in appendices.

Open access This is an open access article distributed in accordance with the Creative Commons Attribution Non Commercial (CC BY-NC 4.0) license, which permits others to distribute, remix, adapt, build upon this work non-commercially, and license their derivative works on different terms, provided the original work is properly cited, appropriate credit is given, any changes made indicated, and the use is non-commercial. See: http://creativecommons.org/licenses/by-nc/4.0/.

\section{ORCID iDs}

Helena Romay Barrero http://orcid.org/0000-0003-2388-2213

María Torres Lacomba http://orcid.org/0000-0002-7051-3130

\section{REFERENCES}

1 Wolfe F. The fibromyalgia syndrome: a consensus report on fibromyalgia and disability. J Rheumatol 1996;23:534-9.

2 Cabo-Meseguer A, Cerdá-Olmedo G, Trillo-Mata JL. Fibromialgia: prevalencia, perfiles epidemiológicos $Y$ costes económicos. Medicina Clínica 2017;149:441-8.

3 Marques AP, Santo AdeSdoE, Berssaneti AA, et al. Prevalence of fibromyalgia: literature review update. Rev Bras Reumatol Engl Ed 2017;57:356-63.

4 Borchers AT, Gershwin ME. Fibromyalgia: a critical and comprehensive review. Clin Rev Allergy Immunol 2015;49:100-51.

5 Clauw DJ. Fibromyalgia: a clinical review. JAMA 2014;311:1547-55.

6 Hofmann SG, Asnaani A, Vonk IJJ, et al. The efficacy of cognitive behavioral therapy: a review of meta-analyses. Cognit Ther Res 2012;36:427-40.

7 Moseley GL, Butler DS. Fifteen years of explaining pain: the past, present, and future. J Pain 2015;16:807-13.

8 Louw A, Zimney K, Puentedura EJ, et al. The efficacy of pain neuroscience education on musculoskeletal pain: a systematic review of the literature. Physiother Theory Pract 2016;32:332-55.

9 Elizagaray-Garcia I, Muriente-Gonzalez J, Gil-Martinez A. [Education for patients with fibromyalgia. A systematic review of randomised clinical trials]. Rev Neurol 2016;62:49-60.

10 Häuser W, Ablin J, Perrot S, et al. Management of fibromyalgia: practical guides from recent evidence-based guidelines. Pol Arch Intern Med 2017;127:47-56.

11 Otte-Trojel T, de Bont A, Rundall TG, et al. How outcomes are achieved through patient portals: a realist review. J Am Med Inform Assoc 2014;21:751-7. 
12 Observatorio Nacional de las Telecomunicaciones $Y$ de la Sociedad de la Información (ONTSI). Estudio sobre opiniones $Y$ expectativas de Los ciudadanos sobre El uso Y La aplicación de las Ti en El ámbito sanitario Edición 2015. Los pacientes Y La e-Sanidad, 2016. https:// www.ontsi.red.es/ontsi/sites/ontsi/files/los_ciudadanos_ante_la_esanidad.pdf

13 Cervantes I. El español: Una lengua viva. Informe 2018. Alcalá de Henares: Instituto Cervantes, 2018. https://cvc.cervantes.es/lengua/ espanol_lengua_viva/pdf/espanol_lengua_viva_2018.pdf

14 Daraz L, MacDermid JC, Wilkins S, et al. Information preferences of people living with fibromyalgia - a survey of their information needs and preferences. Rheumatology Reports2011;3:e7

15 Basavakumar D, Flegg M, Eccles J, et al. Accuracy, completeness and accessibility of online information on fibromyalgia. Rheumatol Int 2019;39:735-42.

16 Daraz L, Macdermid JC, Wilkins S, et al. The quality of websites addressing fibromyalgia: an assessment of quality and readability using standardised tools. BMJ Open 2011;1:e000152.

17 Barrio-Cantalejo IM, Simón-Lorda P, Melguizo M, et al. Validación de la Escala INFLESZ para evaluar La legibilidad de Los textos dirigidos a pacientes. An Sist Sanit Navar 2008;31:135-52.

18 Bermúdez-Tamayo C, Jiménez-Pernett J, García Gutiérrez JF, et al. Cuestionario para evaluar sitios web sanitarios según criterios europeos. Atención Primaria 2006;38:268-74.

19 Charnock D, Shepperd S. Learning to discern online: applying an appraisal tool to health websites in a workshop setting. Health Educ Res 2004;19:440-6.

20 Charnock D, Shepperd S, Needham G, et al. Discern: an instrument for judging the quality of written consumer health information on treatment choices. J Epidemiol Community Health 1999;53:105-11.

21 Bragazzi NL, Amital H, Adawi M, et al. What do people search online concerning the "elusive" fibromyalgia? Insights from a qualitative and quantitative analysis of Google Trends. Clin Rheumatol 2017;36:1873-8.

22 Eysenbach G, Powell J, Kuss O, et al. Empirical studies assessing the quality of health information for consumers on the world wide web: a systematic review. JAMA 2002;287:2691-700.

23 W3C. web content accessibility guidelines 1.0,Secondary Web Content Accessibility Guidelines 1.0., 1999. Available: https://www. w3.org/TR/1999/WAI-WEBCONTENT-19990324/wai-pageauth.html [Accessed 9 Aug 2019].

24 Alliende González F. La legibilidad de Los textos: manual para La evaluación, selección Y elaboración de textos. Santiago de Chile: Andrés Bello, 1994: 1-287.

25 Wolfe F, Smythe HA, Yunus MB, et al. The American College of rheumatology 1990 criteria for the classification of fibromyalgia. Report of the multicenter criteria Committee. Arthritis Rheum 1990;33:160-72.

26 Wolfe F, Clauw DJ, Fitzcharles M-A, et al. The American College of rheumatology preliminary diagnostic criteria for fibromyalgia and measurement of symptom severity. Arthritis Care Res 2010;62:600-10.

27 Castillo-Ortiz JD, Valdivia-Nuno JdeJ, Ramirez-Gomez A, et al. Readability, relevance and quality of the information in Spanish on the web for patients with rheumatoid arthritis. Reumatol Clin 2017:13:139-44.

28 Schreuders EH, Grobbee EJ, Kuipers EJ, et al. Variable quality and readability of patient-oriented websites on colorectal cancer screening. Clin Gastroenterol Hepatol 2017;15:79-85.

29 Bea-Muñoz M, Medina-Sánchez M, Flórez-García MT. Quality of websites with patient information about spinal cord injury in Spanish. Spinal Cord 2016;54:540-5.

30 Hernández-Morante JJ, Jiménez-Rodríguez D, Cañavate R, et al. Analysis of information content and general quality of obesity and eating disorders websites. Nutr Hosp 2015;32:606-15.

31 Minervation L. The LIDA instrument Minervation validation instrument for health care web sites, 2007. Available: http://www.minervation.
com/wp-content/uploads/2011/04/Minervation-LIDA-instrument-v12.pdf [Accessed 29 Aug 2019].

32 Kaicker J, Borg Debono V, Dang W, et al. Assessment of the quality and variability of health information on chronic pain websites using the discern instrument. BMC Med 2010;8:59.

33 Washington TA, Fanciullo GJ, Sorensen JA, et al. Quality of chronic pain websites. Pain Med 2008;9:994-1000.

34 Smith EA, Kincaid JP. Derivation and validation of the automated readability index for use with technical materials. Hum Factors 1970;12:457-564.

35 Flesch R. A new readability yardstick. J Appl Psychol 1948;32:221-33.

36 Szigriszt Pazos F. Sistemas predictivos de legibilidad del mensaje escrito: fórmula de perspicuidad [Thesis]. Madrid: Complutense University of Madrid, 1993: 1-463.

37 Webnode. Webnode, 2019. Available: https://www.webnode.es/ [Accessed 6 Sep 2019].

38 Sallinen M, Kukkurainen ML, Peltokallio L. Finally heard, believed and accepted--peer support in the narratives of women with fibromyalgia. Patient Educ Couns 2011;85:e126-30.

39 Wolfe F. Stop using the American College of rheumatology criteria in the clinic. J Rheumatol 2003;30:1671-2.

40 Kim SY, Busch AJ, Overend TJ, et al. Flexibility exercise training for adults with fibromyalgia. Cochrane Database Syst Rev 2019;9:Cd013419.

41 Macfarlane GJ, Kronisch C, Dean LE, et al. EULAR revised recommendations for the management of fibromyalgia. Ann Rheum Dis 2017;76:318-28.

42 Bidonde J, Busch AJ, Schachter CL, et al. Aerobic exercise training for adults with fibromyalgia. Cochrane Database Syst Rev 2017;6:Cd012700.

43 Conesa Fuentes MdelC, Aguinaga Ontoso E, Hernández Morante $\mathrm{JJ}$, MdelC C, OntosoE A. [An evaluation of the quality of health web pages using a validated questionnaire]. Aten Primaria 2011;43:33-40.

44 Jiménez Pernett J, García Gutiérrez JF, Martín Jiménez JL, et al. Tendencias en El uso de Internet como Fuente de información sobre salud. UOC Papers 2007;4:44-50.

45 Friedman DB, Hoffman-Goetz L. A systematic review of readability and comprehension instruments used for print and web-based cancer information. Health Educ Behav 2006;33:352-73.

46 Ríos Hernández IN. Un acercamiento a la legibilidad de textos relacionados Con El campo de la salud. Chasqui 2017;135:253-73.

47 Thomson MD, Hoffman-Goetz L. Readability and cultural sensitivity of web-based patient decision AIDS for cancer screening and treatment: a systematic review. Med Inform Internet Med 2007;32:263-86.

48 Theodosiou L, Green J. Emerging challenges in using health information from the Internet. Adv psychiatr treat 2003;9:387-96.

49 Graber MA, Roller CM, Kaeble B. Readability levels of patient education material on the world wide web. $J$ Fam Pract 1999;48:58-61.

50 Statcounter. Search engine market share Spain. secondary search engine market share Spain, 2019. Available: https://gs.statcounter. com/search-engine-market-share/all/spain/\#monthly-201808-201908 [Accessed 04 Sep 2019].

51 Statcounter. Search engine market share South America. secondary search engine market share South America, 2019. Available: https:// gs.statcounter.com/search-engine-market-share/all/south-america/\# monthly-201808-201908 [Accessed 04 Sep 2019].

52 Insights $C$. The value of Google result positioning. secondary the value of Google result positioning, 2013. Available: http://info.chitika. com/uploads/4/9/2/1/49215843/chitikainsights-valueofgoogleresults positioning.pdf [Accessed 04 Sep 2019].

53 Tan SS-L, Goonawardene N. Internet health information seeking and the patient-physician relationship: a systematic review. J Med Internet Res 2017;19:e9. 